\title{
HUBUNGAN ANTARA PREFERENSI BELAJAR TERHADAP GANGGUAN DEPRESI DAN GANGGUAN CEMAS PADA MAHASISWA PREKLINIK SUATU FAKULTAS KEDOKTERAN
}

\author{
Carissa Faustina, Dharmady Agus \\ Fakultas Kedokteran Universitas Katolik Indonesia Atmajaya, Jakarta - INDONESIA
}

\begin{abstract}
Background: Students have different learning preferences in terms of assimilation and processing information. VARK learning preferences, which were introduced by Fleming, can identify learning preferences based on sensory modality. The model categorizes students into four different learning preferences, namely visual, aural, read/write, and kinesthetic. In his book, Westwood stated that the wrong application of learning preferences may lead to depressive disorder and anxiety disorder.
\end{abstract}

Method: This study is a cross sectional study. The study was conducted by interviewing respondents to determine whether they have depressive disorder and anxiety disorder. Respondents will fill up a VARK questionnaire to determine their learning preferences. Samples will be collected from as many as 260 pre-clinical student of faculty of medicine of Atma Jaya Catholic University of Indonesia. Data will be collected and analyzed by using Chi Square test.

Results: The result showed that there is no significant relationship between learning preferences and depressive disorder $(p=1,000)$, as well as anxiety disorder $(p=0,477)$.

Conclusion: There is no relationship between learning preferences and depressive disorder, as well as anxiety disorder.

Keywords: learning preferences, depressive disorder, anxiety disorder, preclinical student

\begin{abstract}
ABSTRAK
Latar belakang: Mahasiswa memiliki preferensi belajar yang berbeda dalam asimilasi dan pengolahan informasi. Model preferensi belajar VARK yang diperkenalkan oleh Fleming mengidentifikasi preferensi belajar berdasarkan modalitas sensorik. Model ini mengklasifikasikan mahasiswa ke dalam empat preferensi belajar yang berbeda yakni visual, aural, read/write, dan kinesthetic. Westwood di dalam bukunya menyatakan bahwa penerapan preferensi belajar yang salah dapat menyebabkan kegagalan dan frustrasi pada mahasiswa, yang akan menimbulkan gangguan depresi dan gangguan cemas.

Metode: Penelitian ini adalah penelitian cross sectional. Penelitian dilakukan dengan mewawancarai responden untuk mengetahui apakah terdapat gangguan depresi dan gangguan cemas dan responden mengisi kuesioner VARK untuk mengetahui preferensi belajarnya. Sampel yang dibutuhkan adalah sebanyak 260 mahasiswa dikumpulkan dan dianalisis dengan menggunakan uji Chi Square.

Hasil: Hasil penelitian menunjukkan bahwa tidak terdapat hubungan yang bermakna antara preferensi belajar terhadap gangguan depresi $(p=1,000)$ dan gangguan cemas $(p=0,477)$.

Kesimpulan: Tidak terdapat hubungan antara preferensi belajar terhadap gangguan depresi dan gangguan cemas.
\end{abstract}

Kata kunci: preferensi belajar, gangguan depresi, gangguan cemas, mahasiswa kedokteran preklinik

Contact: carissafaustina@yahoo.com 


\section{PENDAHULUAN}

Seiring dengan berkembangnya zaman, pendidikan menjadi sektor yang penting dalam mengembangkan kehidupan manusia dan juga dalam meningkatkan kemajuan suatu negara. Pendidikan merupakan proses interaksi belajar mengajar yang bertujuan untuk meningkatkan perkembangan mental sehingga menjadi individu yang mandiri dan utuh. Oleh karena itu, peningkatan mutu dalam pendidikan sangat penting untuk menghasilkan sumber daya manusia yang berkualitas. Sumber daya manusia yang berkualitas akan dapat meningkatkan perekonomian dan kehidupan suatu negara. ${ }^{1}$

Salah satu unsur yang penting dalam pendidikan adalah proses pembelajaran. Dalam peraturan pemerintah Republik Indonesia nomor 32 tahun 2013 pasal 1 ayat 19 tentang perubahan atas peraturan pemerintah nomor 19 tahun 2005, pembelajaran adalah proses interaksi antar peserta didik dengan pendidik dan sumber belajar pada suatu lingkungan belajar. ${ }^{2}$

Siswa memiliki preferensi belajar yang berbeda dalam asimilasi dan pengolahan informasi. Model preferensi belajar VARK yang diperkenalkan oleh Fleming mengidentifikasi preferensi belajar berdasarkan modalitas sensorik. Model ini mengklasifikasikan siswa ke dalam empat preferensi belajar yang berbeda yakni visual (V) yaitu belajar dengan melihat, aural (A) yaitu belajar dengan mendengar, read/write $(R)$ yaitu belajar dengan membaca atau menulis, dan kinesthetic $(\mathrm{K})$ yaitu belajar dengan aplikasi. ${ }^{3}$ Westwood di dalam bukunya menyatakan bahwa penerapan preferensi belajar yang salah dapat menyebabkan kegagalan dan frustrasi pada mahasiswa, yang akan menimbulkan gangguan depresi dan gangguan cemas. ${ }^{4}$ Mahasiswa kedokteran saat ini memiliki keragaman yang luas dalam hal usia, pengalaman, budaya, etnis, dan preferensi belajar, serta gaya belajar. Hal itu juga menyajikan tantangan tersendiri bagi dosen untuk memenuhi kebutuhan pendidikan semua mahasiswa. Preferensi belajar dan gaya belajar mahasiswa yang tepat dapat meningkatkan kinerja mahasiswa. Dengan preferensi belajar mahasiswa yang berbeda menjadikan dosen memiliki tanggung jawab yang lebih untuk mengembangkan preferensi yang tepat. ${ }^{5}$ Setiap preferensi belajar merupakan aspek yang unik dari pembelajaran dan hal ini menjadi dasar untuk mengetahui bahwa preferensi belajar seseorang individu dapat mencakup kombinasi dari model ini. Beberapa peserta didik memiliki preferensi untuk salah satu dari preferensi belajar ini (peserta didik unimodal), sedangkan peserta didik multimodal tidak memiliki preferensi yang kuat untuk setiap metode tunggal. Mereka dapat memiliki dua atau lebih preferensi belajar. Peserta didik multimodal dibagi menjadi bimodal, trimodal, dan quadmodal, yang lebih memilih untuk menggunakan dua, tiga, atau empat preferensi belajar. ${ }^{6}$ Kesulitan-kesulitan tersebut akan terukur melalui gangguan depresi dan gangguan cemas apabila ketidaksesuaian preferensi belajar ini menjadi salah satu sumber stres bagi mahasiswa yang memiliki preferensi belajar tertentu.

Perludiketahuibahwabeberapapenelitian mengenai prevalensi gangguan depresi dan gangguan cemas sudah dilakukan di berbagai negara dan di beberapa fakultas kedokteran di Indonesia. Penelitian yang dilakukan di Estonia, menunjukkan bahwa 30,6\% mahasiswa kedokteran mengalami gangguan depresi dan 21,9\% mengalami gangguan cemas. ${ }^{7}$ Sementara itu penelitian di Fakultas Kedokteran Universitas Selcuk, Turki menunjukkan bahwa 20,3\% mahasiswa kedokteran memiliki gangguan cemas, dan 29,3\% memiliki gangguan depresi. ${ }^{8}$

Di Indonesia, Fakultas Kedokteran Universitas Katolik Indonesia Atma Jaya telah melakukan penelitian prevalensi gangguan depresi pada angkatan 2007. Hasilnya adalah 34,9\% mahasiswa tersebut memiliki gangguan depresi. ${ }^{9}$ Selain itu, Universitas Tanjungpura juga mengukur prevalensi gangguan depresi pada mahasiswanya. Prevalensi gangguan depresi adalah 30,8\% yang terdiri atas $15,4 \%$ depresi ringan, $13 \%$ depresi sedang, dan $2,4 \%$ depresi berat. ${ }^{10}$

Oleh karena itu, peneliti ingin meneliti apakah terdapat hubungan antara preferensi belajar berdasarkan modalitas sensorik terhadap gangguan depresi dan gangguan cemas pada mahasiswa preklinik FKUAJ tahun 2015. 


\section{METODE}

Desain penelitian yang digunakan untuk mengetahui adanya hubungan antara preferensi belajar terhadap gangguan depresi dan gangguan cemas pada mahasiswa preklinik Fakultas Kedokteran Universitas Katolik Indonesia Atma Jaya Tahun 2015 adalah desain cross sectional. Penelitian ini dilaksanakan dengan membagikan kuesioner yang diisi oleh responden. Penelitian ini dilakukan di Fakultas Kedokteran Universitas Katolik Indonesia Atma Jaya Jakarta, Jalan Pluit Raya No. 2, Jakarta Utara. Sampel diambil secara simple random sampling dimana setiap anggota atau unit dari populasi memiliki kesempatan yang sama untuk dipilih sebagai target.

\section{HASIL DAN PEMBAHASAN}

Penelitian dilakukan pada bulan Desember 2015 Maret 2016 terhadap mahasiswa FKUAJ angkatan 2012, 2013, 2014, dan 2015. Total 260 mahasiswa dari empat angkatan mahasiswa preklinik FKUAJ yang memenuhi kriteria penelitian diminta untuk mengisi kuesioner dan peneliti mengumpulkan data dari kuesioner yang dibagikan. Karakteristik responden penelitian dapat dilihat pada tabel 1 .

Tabel 1. Karakteristik Responden

\begin{tabular}{llcl} 
& \multicolumn{3}{c}{$\begin{array}{c}\text { Frekuensi } \\
\text { (n) }\end{array}$} \\
Jenis Kelamin & Laki-laki & 106 & $40.7 \%$ \\
& Perempuan & 154 & $59.3 \%$ \\
\hline Angkatan & 2012 & 65 & $25 \%$ \\
& 2013 & 60 & $23.1 \%$ \\
& 2014 & 70 & $26.9 \%$ \\
& 2015 & 65 & $25 \%$ \\
\hline Preferensi & Unimodal & 121 & $46.5 \%$ \\
belajar & Multimodal & 139 & $53.5 \%$ \\
\hline Gangguan & Ya & 43 & $16.5 \%$ \\
depresi & Tidak & 217 & $83.5 \%$ \\
\hline Gangguan & Ya & 66 & $25.4 \%$ \\
cemas & Tidak & 194 & $74.6 \%$ \\
\hline
\end{tabular}

Hasil penelitian ini menunjukkan bahwa tidak terdapat hubungan yang bermakna antara preferensi belajar dan gangguan depresi pada mahasiswa preklinik FKUAJ tahun $2015(\mathrm{p}=1,000)$, seperti yang dapat dilihat pada Tabel 2 .
Tabel 2. Preferensi Belajar Terhadap Gangguan Depresi

\begin{tabular}{|c|c|c|c|c|}
\hline & \multicolumn{2}{|c|}{ Gangguan Depresi } & \multirow[b]{2}{*}{$\mathrm{p}$} \\
\hline & & $\begin{array}{c}(+) \\
n(\%)\end{array}$ & $\begin{array}{c}(-) \\
\text { n }(\%)\end{array}$ & \\
\hline \multirow{2}{*}{$\begin{array}{l}\text { Preferensi } \\
\text { belajar }\end{array}$} & $\begin{array}{l}\text { Uni } \\
\text { modal }\end{array}$ & $\begin{array}{c}20 \\
(16,53 \%) \\
\end{array}$ & $\begin{array}{c}101 \\
(83,47 \%) \\
\end{array}$ & \multirow{2}{*}{1,000} \\
\hline & $\begin{array}{l}\text { Multi } \\
\text { modal }\end{array}$ & $\begin{array}{c}23 \\
(16,55 \%)\end{array}$ & $\begin{array}{c}116 \\
(83,45 \%)\end{array}$ & \\
\hline
\end{tabular}

Pada tabel 3 dipaparkan bahwa tidak terdapat hubungan yang bermakna antara preferensi dan gangguan cemas pada mahasiswa preklinik FKUAJ tahun $2015(\mathrm{p}=0,477)$.

Tabel 3. Preferensi Belajar Terhadap Gangguan Cemas

\begin{tabular}{llccc} 
& & \multicolumn{2}{c}{ Gangguan Cemas } & \\
\cline { 3 - 4 } & & $(+)$ & $\mathbf{( - )}$ & $\mathbf{p}$ \\
& & $\mathbf{n}(\%)$ & $\mathbf{n}(\%)$ & \\
\multirow{3}{*}{$\begin{array}{llcc}\text { Preferensi } \\
\text { belajar }\end{array}$} & Uni & 28 & 93 \\
& modal & $(23,14 \%)$ & $(76,86 \%)$ & 0,477 \\
\cline { 2 - 4 } & Multi & 38 & 101 & \\
\hline
\end{tabular}

Tabel 4 menunjukkan bahwa preferensi belajar mahasiswa preklinik Fakultas Kedokteran Universitas Katolik Indonesia Atma Jaya mayoritas adalah multimodal sebesar $53,46 \%$ dan unimodal sebesar $46,54 \%$.

Tabel 4. Proporsi Preferensi Belajar Mahasiswa Preklinik

\section{Preferensi Belajar Jumlah Persentase (\%)}

\begin{tabular}{lcc} 
Unimodal & 121 & 46,54 \\
Multimodal & 139 & 53,46 \\
\hline Jumlah & 260 & 100 \\
\hline
\end{tabular}

Tabel 5 menunjukkan bahwa apabila ditinjau dari unimodal, distribusi frekuensi preferensi belajar yang terbanyak adalah kinesthetic $(38,84 \%)$, disusul aural $(37,19 \%)$, read/write $(14,05 \%)$, dan yang terakhir adalah visual $(9,92 \%)$. 
Tabel 5. Proporsi Preferensi Belajar Unimodal Mahasiswa Preklinik

\begin{tabular}{lcc} 
Preferensi Belajar & Jumlah & Persentase (\%) \\
Visual & 12 & 9,92 \\
Aural & 45 & 37,19 \\
Read/Write & 17 & 14,05 \\
Kinesthetic & 47 & 38,84 \\
\hline Jumlah & 121 & 100 \\
\hline
\end{tabular}

Di masa lalu, metode studi terbatas pada kuliah, tutorial dan belajar sendiri. Asal pengetahuan sangat tergantung pada kuliah. Saat ini perkembangan teknologi informasi memudahkan mahasiswa mengakses berbagai sumber pengetahuan. Kemudahan tersebut membuat perubahan adaptasi belajar pada mahasiswa yang lebih baik. Di Asia, siswa tidak luput dari kemajuan teknologi, karena itu preferensi belajar mereka juga berubah seiring dengan kemajuan ini. Banyak lembaga pendidikan tinggi di Asia sudah mengadopsi kemajuan informasi teknologi sebagai salah satu cara memberikan pembelajaran dan penilaian pada mahasasiswa. ${ }^{11}$

Banyak faktor seperti organisasi, lingkungan, teknologi informasi, dan pribadi yang dapat mengembangkan sikap untuk menerima sistem pembelajaran baru. Penelitian ini juga menunjukkan bahwa bila mahasiswa memiliki kesabaran, disiplin diri dan kepercayaan diri, kemudahan menggunakan perangkat lunak, dukungan sebaya, keterampilan teknis dan kemampuan manajemen waktu yang baik dapat membuat preferensi belajar tidak terlalu berpengaruh pada dirinya. Hal ini sesuai dengan penelitian Ndume et al. ${ }^{12}$

Student Centered Learning FKUAJ yang diperbaharui mulai tahun akademik 2012 dapat memromosikan metode pembelajaran strategis antar mahasiswa preklinik FKUAJ. Strategi Student Centered Learning yang baru dengan metode diskusi seperti Cased Based Discussion dan Case Base Learning telah menciptakan pembelajaran yang lebih baik. ${ }^{11}$ Selain metode tersebut, tatap muka dalam perkuliahan konvensional juga terbukti efektif karena mahasiswa mendapatkan informasi langsung dari pengajar yang memiliki keahlian dan pengalaman di bidangnya sehingga dapat meningkatkan task value, self efficacy, dan intrinsic goal orientation mahasiswa.
Problem Based Learning sebagai salah satu metode pembelajaran Student Centered Learning yang sudah lebih dulu diterapkan dapat memfasilitasi tidak hanya pengembangan keterampilan pemecahan masalah, tetapi juga menambah ilmu pengetahuan, keterampilan komunikasi, dan kemandirian dalam belajar. ${ }^{13}$ Begitu pula dengan Case Base Learning (CBL), juga meningkatkan motivasi belajar mahasiswa karena CBL membuat mahasiswa dapat meningkatkan kepercayaan diri dimana mahasiswa mendapat kesempatan untuk membagikan pengetahuan yang sudah dipelajarinya kepada mahasiswa lainnya. CBL membantu mahasiswa untuk menerapkan teori dengan dibantu contoh kasus. ${ }^{14}$ Berbagai metode tersebut tampaknya memengaruhi rendahnya gangguan depresi dan gangguan cemas di mahasiswa preklinik FKUAJ.

\section{KESIMPULAN}

Menurut uji Chi Square menujukkan bahwa tidak terdapat hubungan antara preferensi belajar terhadap gangguan depresi pada mahasiswa FKUAJ tahun 2015 ( $\mathrm{p}=1,000)$. Menurut uji Chi Square menujukkan bahwa tidak terdapat hubungan antara preferensi belajar terhadap gangguan cemas pada mahasiswa FKUAJ tahun $2015(\mathrm{p}=0.477)$. Apabila ditinjau dari preferensi belajar unimodal, proporsi preferensi belajar tertinggi adalah preferensi belajar kinesthetic. Dapat disimpulkan bahwa tidak terhadapat hubungan antara preferensi belajar terhadap gangguan depresi dan gangguan pada mahasiswa FKUAJ tahun 2015.

\section{DAFTAR PUSTAKA}

1. Dwi Prasetya F. Pengaruh gaya belajar terhadap prestasi belajar mata diklat listrik otomotif siswa kelas xi teknik perbaikan bodi otomotif smkn 2 depok sleman. [Yogyakarta]: Fakultas Teknik Universitas Negri Yogyakarta; 2012.

2. Universitas Indonesia. Peraturan pemerintah Republik Indonesia nomor 32 tahun 2013 tentang perubahan atas peraturan pemerintah nomor 19 tahun 2005. UI; 2013.

3. Prithishkumar I, Michael S. Understanding your student: Using the VARK model. J Postgrad Med. 2014;60(2):183-6. 
4. Westwood P. Learning and learning difficulties. Univ Hongkong. 2004;

5. Lujan HL, DiCarlo SE. First-year medical students prefer multiple learning styles. Adv Physiol Educ. 2006;30(1):13-6.

6. Ganesh A, Ratnakar UP. Learning preferences of PG and UG students: application of VARK. SCMS J Indian Manag. 2014;11(3):26-36.

7. Eller T, Aluoja A, Vasar V, Veldi M. Symptoms of anxiety and depression in Estonian medical students with sleep problems. Depress Anxiety. 2006;23(4):250-6.

8. Karaoglu N, Seker M. Anxiety and depression in medical students related to desire for and expectations from a medical career. West Indian Med J. 2010 Mar;59(2):196-202.

9. Hariyanto AD, Surjadi C, Joewana S. Prevalensi depresi dan faktor yang mempengaruhi pada mahasiswa fakultas kedokteran universitas katolik Indonesia atma jaya angkatan 2007 [skripsi]. [Jakarta]: Fakultas Kedokteran Universitas Katolik Indonesia Atma Jaya; 2010.

10. Prevalensi dan faktor faktor risiko yang berhubungan dengan tingkat gejala depresi pada mahasiswa program studi pendidikan dokter fakultas kedokteran universitas tanjungpura [skripsi]. [Pontianak]: Fakultas Kedokteran Universitas Tanjungpura; 2014.

11. Liew S-C, Sidhu J, Barua A. The relationship between learning preferences (styles and approaches) and learning outcomes among preclinical undergraduate medical students. BMC Medical Education. 2015;15:44.

12. Seyal AH, A Rahman MN. Understanding Learning Styles, Attitudes and Intentions in Using e-Learning System: Evidence from Brunei. World Journal of Education. 2015;5(3).

13. Syah NA. Konsistensi Kurikulum pada ProblemBased Learning (PBL). Jurnal Pendidikan Kedokteran dan Profesi Kesehatan Indonesia. 2008;3.

14. Suhoyo Y, Emilia O. Perbandingan Efektifitas antara Computer Based Learning dan Kuliah sebagai Metode Pengajaran Bioetika pada Mahasiswa Baru Fakultas Kedokteran Universitas Gadjah Mada. Jurnal Pendidikan Kedokteran dan Profesi Kesehatan Indonesia. 2008:3:157-65. 